\title{
An Investigation of Academic Dishonesty in a South African Institution
}

\author{
Chao Feramo Nkhungulu, Fadzai Deda \\ University of Cape Town, South Africa
}

\begin{abstract}
Academic dishonesty has generated a lot of interest over the past two decades. A descriptive cross section design was used. The sample was under-graduate students from different faculties residing in the institution's hostels. SPSS was used for all data analyses. All measures were valid and reliable. Pearson product correlations and coefficients, and regression analyses were used to test the hypothesis. Results: Students considered academic dishonesty in monitored situation to be a serious offence compared to unmonitored situations. Students indicated that cheating in certain assessments (examinations) were considered more serious than in others (tutorials). The issue of cyber plagiarism and use of technology were the commonly identified forms of academic dishonesty and acknowledged to be commonly undertaken. Findings revealed that direct and indirect attitudes had a significant inverse relationship with intentions to engage in academic dishonesty.. The study established that a student's justification for engaging in academic dishonesty mediated Theory of Planned Behaviour variables - attitudes, subjective norms, perceived behavioural control and intentions to engage in academic dishonesty. Students' intention to engage in academic dishonesty was further influenced by sanctions or lack of these from the relevant faculty. Conclusion: Study findings are important for institutions to consider relevant interventions to safe guard academic quality and reputation.
\end{abstract}

\section{Introduction}

This study examined undergraduate student perceptions of academic dishonesty (AD) in a South African tertiary institution. The problem of $\mathrm{AD}$ has been of great interest for many decades which remains a relevant topic for tertiary institutions, as it is on the increase [1]. Academic dishonest has been defined as a multifaceted construct with different aspects and forms which include plagiarism [2] copying of assignments or tests [3], communication of answers [4], use of fraudulent excuses [5], and the unauthorised use of different types of technology in tests or assignments [6]. This study defined AD as the use of unethical methods to gain unfair advantage over other students for the purpose of advancing ones academic career [7]. The multiplicity of terms used to describe AD is well documented [8]. Studies have reported on student perceptions of $\mathrm{AD}$ as nonexistent outside the ambit of examination situations [8]. The adoption of a "cheating is normal attitude" has been identified as a factor in the increase of $\mathrm{AD}$ [9] indicated that a majority of students cheat at some point in their college careers. This is despite many institutions having implemented policies and honour codes on AD [1]. This study uses the term cheating synonymously with AD.

There has been a great interest by researchers to understand and explain why students cheat and the factors that influence them to cheat [10]. Factors that have been reported as influencing AD include age, gender, grade-point-average, membership of sororities and fraternities [11]. Other factors include self-control, honour codes and policies on $\mathrm{AD}$, technology [12] and personality [13]. Despite having knowledge on all these factors, AD may be better understood in the environment in which it takes place because of the cultural bias that impacts ethical decision making [14]. There is a dearth of knowledge on the factors that influence AD in the South African context. To investigate $\mathrm{AD}$, this study used the Theory of Planned Behaviour (TPB) [15] as a framework to investigate intentions to commit AD. To predict $\mathrm{AD}$, researchers have used the TPB which has been proven to be an effective theory for predicting intentions of social dishonest behaviours [16] Central to TPB is the notion that intention is an antecedent to behaviour [17]. The theory identifies three constructs that inform behaviour and influence intentions to enact the behaviour: attitudes towards the particular behaviour; subjective norms and perceived behavioural control [18]. According to TPB, the more favourable the attitude and subjective norm towards the behaviour and the greater the perceived behavioural control, the stronger an individual's intention to perform the target behaviour. Intentions explain the motivations to people's behaviour and the energy they are willing to expend in performing the particular behaviour.

The value attached to grades obtained has been reported to motivate students to cheat, that the understanding gained from the course is not considered [18]. This notion has been supported by other researchers who reported that there is an increase in the competitiveness of society which has resulted in education being a means to an end. The competition has resulted in pressure on the students to get high grades, to enable them to get into a chosen career path with top organisations [3]. In 
order to gain a competitive advantage, reported an increase in cheating if the consequences of $\mathrm{AD}$ were perceived as insignificant.

The perceived social pressure to engage in $\mathrm{AD}$ is influenced by normative beliefs of those considered significant to the student who will approve or disapprove of the behaviour [19]. Previous studies reported that $\mathrm{AD}$ was associated with peer approval more than individual attributes. This is reinforced by the belief that everybody's cheating and engaging in $\mathrm{AD}$ therefore increasing the student's intention to engage in $A D$ behaviour. This is reported to influence students who belong to social organisations such as residence halls, fraternities, sororities or clubs to engage in [1]. These organisations act as learning environments for norms, values, and skills associated with $\mathrm{AD}$ and provide students with access to people and resources that can encourage cheating behaviours. This study hypothesised that there will be a significant relationship between subjective norms and intentions to engage in AD.

In a study of $\mathrm{AD}$ [15], $\mathrm{PBC}$ is reported as an important variable for understanding $\mathrm{AD}$. For students to engage in $\mathrm{AD}$, they need to believe that they are in control of the situation and they that they have the necessary resources to engage in $\mathrm{AD}$ without being caught [15]. To determine whether the TPB was a good predictor of student intention to engage in $\mathrm{AD}$, this study hypothesised that there will be significant relationship between TPB variables and AD (hypothesis 2).

In an investigation of monitored and unmonitored assessment situations, Harding et al [14] reported higher frequencies of cheating in unmonitored context than in the monitored context. According to [19], privacy was an important factor which influenced the decision to engage in AD. Activities such as cheating on assignments is an unmonitored and private activity were individual influences are greater than the social norms. The current study hypothesised that situational factors will predict student intention to engage in AD (hypothesis 3).

According to [19], students who engaged regularly in AD used justification. The influence of attitudes, subjective norms and PBC were mediated by a students' ability to justify prior cheating which results in neutralising attitudes to AD.

Moral obligation was considered important for intention to engage in unethical behaviours such as $\mathrm{AD}$, lying to avoid taking a test or submit an assignment on time [17] The influence of moral obligation on whether to engage in $\mathrm{AD}$ or not, indicates that students realise that cheating is wrong [19]. This study hypothesized that moral obligation will increase the predictive significant of TPB (hypothesis 4).

Investigations of the role of gender have not reported any differences in cheating behaviour; although [11] findings reported that men cheated more than women and undergraduate students were more likely to cheat than graduate students were observed. First and second year students were reported to find it easy to cheat in an elective course that they do not enjoy, while final year students were more enthusiastic about their work closer to graduation [10]. This study hypothesised that there will be significant differences between students in different academic year of study (hypothesis 5).

\section{Method}

A cross sectional descriptive research design was used. Convenience sampling of undergraduate students residing in single sex residences was used to draw the sample. A self-administered questionnaire was subjected to a pilot study. Ethics clearance was obtained from the research in ethics committee of the commerce faculty data collection commenced. Participation was voluntary and anonymity of the respondents was guaranteed.

\section{Measures}

A forced scale was considered appropriate because $\mathrm{AD}$ is an ethical issue as it deals with right and wrong, such a measure obliged participants to choose for or against AD [1]. All scales used a 4 point Likert scale except for the direct attitudes scale which used a 7 - point semantic differential scale.

To measure respondent's knowledge of $\mathrm{AD}$ behaviours eight of Etter et al., twenty-four items were used $(\alpha=.75)$. A semantic differential scale consisting of five sets of opposites adapted from Beck and Ajzen [15] were used to measure direct attitudes towards $\mathrm{AD}$ in the homework context $(\alpha=$ $.80)$ and test context $(\alpha=.76)$. To measure indirect attitudes towards $\mathrm{AD}(\alpha=.75)$, six items derived from Stone et al [19] were added to the instrument.

Five items adapted from [14] were used to measure subjective norms for the test context $(\alpha=$ .72) and homework context $(\alpha=.75)$. These measures solicited information on the expectations held by family, friends, colleagues, teachers and the perceived social pressure to comply with these expectations [15].

To measure control beliefs, two items from [16] and two items from [17] were combined to assess the respondent's confidence to engage in $\mathrm{AD}$ successfully in the test context $(\alpha=.52)$ and homework situation $(\alpha=.73)$. Subjective selection was used in deciding which items would be suitable to measure intentions for this study.

Two items adapted from [17] were used to assess respondent's intentions to engage in $\mathrm{AD}$ in the test $(\alpha$ $=.55)$ and homework $(\alpha=.60)$ context. Three items adapted from [17], were used to solicit information on how respondent's moral obligation affects intentions in the test $(\alpha=.50)$ and homework $(\alpha=$ 
.55) contexts. Face validity was used in deciding which items would be suitable for the study. Seven items adapted from were used to measure justification for engaging in $\operatorname{AD}(\alpha=.82)$.

\section{Data Collection}

A sample from the 2010 winter term was used for the pilot study. Of the 110 pilot questionnaires distributed, 61 completed questionnaires were collected representing a $55.45 \%$ response rate. The main study sampled undergraduate students resident in single gender residences. Of the 230 questionnaires distributed, 182 completed questionnaires were returned representing a $79.13 \%$ response rate. The high response rate is attributed to administration of the questionnaire during meal times in the dining hall.

\section{Results}

Participants in this study were aware that cyberplagiarism $(68 \%, n=166)$, the use of technology to store notes and answers $(69 \%, \mathrm{n}=167)$, and copying directly from other students $(68 \%, \mathrm{n}=165)$ is dishonest behaviour. Plagiarism was considered dishonesty behaviour but students were not certain of degree with $30.7 \%(n=74)$ reporting that it was very dishonest and $37.8 \%(\mathrm{n}=91)$ reported it as extremely dishonest.

The most common academic dishonest behaviour reported was that of copying another student's homework assignment. $20 \%(\mathrm{n}=48)$ indicated that they had engaged in this AD behaviour once, $40 \%$ (n $=94)$ said a few times, $8 \%(n=19)$ admitted to engaging in it all the time. Of the surveyed students, $34 \%$ reported they were likely to engage in AD to avoid being refused permission to write the final exam $31 \%$ indicated they were mostly like to behave in a similar manner.

Respondents reported that they were likely to engage in $\mathrm{AD}$ behaviour for fear of failure $35 \%$ while $20 \%$ indicated they would most likely commit AD. When responding to engaging in $\mathrm{AD}$ due to time constraints $38 \%$ indicated they were likely to do so and $18 \%$ were most likely to engage in $\mathrm{AD}$ for time constraints. Respondents' were less willing to justify engaging in $\mathrm{AD}$ due to laziness to do their work $46 \%$; peer pressure $47 \%$; and because other students are doing it $47 \%$.

Observed significant relationships between direct attitudes (DA), indirect attitudes (IA), subjective norm (SN), perceived behavioural control (PBC) and intentions to engage in $\mathrm{AD}$, supported hypothesis made. DA $(\mathrm{r}=-.50, \mathrm{p}<.01)$ and IA $(\mathrm{r}=-.45, \mathrm{p}<.01)$ show a moderate inverse relationship with intentions. As hypothesized, there is a moderate positive relationship between $\mathrm{SN}$ and intentions $(\mathrm{r}=.42, \mathrm{p}<$ $.01)$ to engage in AD. The relationship between PBC and intentions $(\mathrm{r}=.21, \mathrm{p}<.01)$ is small and positive. Intentions to engage in $\mathrm{AD}$ was found to have a small and positive relationship with justifications ( $\mathrm{r}$ $=.31, \mathrm{p}<.01)$ and behavioural self-reports $(\mathrm{SR})(\mathrm{r}=$ $.36, \mathrm{p}<.01)$. Moral obligation (MO) has a moderate inverse relationship with intentions $(\mathrm{r}=-.50, \mathrm{p}<$ $.01)$.

Statistically significant relationships were found between subjective norms, PBC, direct and indirect attitudes and intentions to engage in $\mathrm{AD}$. Intention to engage in $\mathrm{AD}$ and direct attitudes $(\mathrm{r}=-.47, \mathrm{p}<01)$ and indirect attitudes $(\mathrm{r}=-.46, \mathrm{p}<01)$ have a relatively moderate inverse relationship. Moderate positive relationships were also found between subjective norm and intention $(\mathrm{r}=.43, \mathrm{p}<01)$, and between PBC and intentions $(r=.47, p<01)$. The relationship between moral obligation and intention to engage in $\mathrm{AD}$ is a moderate but inverse one $(\mathrm{r}=\mathrm{-}$ $.65, \mathrm{p}<01)$. Moderate positive relationships are shown between moral obligation and direct attitudes $(\mathrm{r}=.41, \mathrm{p}<01)$ and indirect attitudes $(\mathrm{r}=.40, \mathrm{p}<$ 01). PBC has a positive relationship with justification $(\mathrm{r}=.42, \mathrm{p}<01)$ and behaviour selfreports $(\mathrm{r}=.37, \mathrm{p}<01)$. (hypotheses $1,2,3$ supported).

\section{Multiple regression analysis}

The results of the hierarchical multiple regression analysis reported in Table 2 show that TPB without moral obligation accounts for $37 \%$ of the variance in intentions to engage in AD. In terms of individual relationships between independent variables and intentions to engage in $\mathrm{AD}$, direct attitudes $(\mathrm{t}=$ $4.23, \mathrm{p}<.001)$ and indirect attitudes $(\mathrm{t}=-3.7, \mathrm{p}<$ $.001)$ were statistically significant. Results are presented in Table 1.

Table 1. Regression Analysis: Predicting Intentions to Engage in $\mathrm{AD}$

\begin{tabular}{|c|c|c|c|c|c|c|c|c|c|c|}
\hline Step 1 & & & & & & 23 & 0.6 & 0.4 & 0.36 & 0.374 \\
\hline Constant & 3.58 & 0.54 & & 6.66 & 0 & & & & & \\
\hline $\begin{array}{l}\text { Subjective } \\
\text { Norm }\end{array}$ & 0.14 & 0.1 & 0.11 & 1.45 & 0.15 & & & & & \\
\hline PBC & 0.12 & 0.08 & 0.09 & 1.39 & 0.17 & & & & & \\
\hline Direct Attitudes & 0.27 & 0.06 & -0.33 & 4.23 & $.000^{*}$ & & & & & \\
\hline $\begin{array}{l}\text { Indirect } \\
\text { Aftitudes }\end{array}$ & 0.36 & 0.09 & -0.27 & -3.7 & $.000^{*}$ & & & & & \\
\hline Step 2 & & & & & & 21 & 0.6 & 0.4 & 0.39 & 0.035 \\
\hline Constant & 4.14 & 0.56 & & 7.45 & 0 & & & & & \\
\hline $\begin{array}{l}\text { Subjective } \\
\text { Norm }\end{array}$ & 0.06 & 0.1 & 0.04 & 0.56 & 0.58 & & & & & \\
\hline PBC & 0.13 & 0.08 & 0.1 & 1.54 & 0.13 & & & & & \\
\hline Direct Attitudes & 0.23 & 0.06 & -0.29 & -3.7 & $.000^{*}$ & & & & & \\
\hline $\begin{array}{l}\text { Indirect } \\
\text { Attitudes }\end{array}$ & 0.26 & 0.1 & -0.19 & -2.6 & $.01^{* *}$ & & & & & \\
\hline $\begin{array}{l}\text { Moral } \\
\text { Obligation }\end{array}$ & 0.26 & 0.08 & -0.24 & 3.01 & 0 & & & & & \\
\hline
\end{tabular}


Table 2. Regression Analysis: Predicting Intentions to Engage in $\mathrm{AD}$

\begin{tabular}{|c|c|c|c|c|c|c|c|c|c|c|}
\hline & $\bar{B}$ & SE B & $\bar{\beta}$ & $\bar{t}$ & $\bar{p}$ & $\bar{F}$ & $\bar{R}$ & $\overline{R^{2}}$ & $\mathrm{AR}^{2}$ & $R^{2} \mathrm{C}$ \\
\hline Step 1 & & & & & & 23 & 0.6 & 0.4 & 0.36 & 0.374 \\
\hline Constant & 3.58 & 0.54 & & 6.66 & 0 & & & & & \\
\hline $\begin{array}{l}\text { Subjective } \\
\text { Norm }\end{array}$ & 0.14 & 0.1 & 0.11 & 1.45 & 0.15 & & & & & \\
\hline PBC & 0.12 & 0.08 & 0.09 & 1.39 & 0.17 & & & & & \\
\hline Direct Attitudes & -0.27 & 0.06 & -0.33 & -4.23 & $.000^{*}$ & & & & & \\
\hline $\begin{array}{l}\text { Indirect } \\
\text { Attitudes }\end{array}$ & -0.36 & 0.09 & -0.27 & -3.7 & $.000^{*}$ & & & & & \\
\hline Step 2 & & & & & & 21 & 0.6 & 0.4 & 0.39 & 0.035 \\
\hline Constant & 4.14 & 0.56 & & 7.45 & 0 & & & & & \\
\hline $\begin{array}{l}\text { Subjective } \\
\text { Norm }\end{array}$ & 0.06 & 0.1 & 0.04 & 0.56 & 0.58 & & & & & \\
\hline PBC & 0.13 & 0.08 & 0.1 & 1.54 & 0.13 & & & & & \\
\hline Direct Attitudes & -0.23 & 0.06 & -0.29 & -3.7 & $.000^{*}$ & & & & & \\
\hline $\begin{array}{l}\text { Indirect } \\
\text { Attitudes }\end{array}$ & -0.26 & 0.1 & -0.19 & -2.6 & $.01^{* *}$ & & & & & \\
\hline $\begin{array}{l}\text { Moral } \\
\text { Obligation }\end{array}$ & -0.26 & 0.08 & -0.24 & -3.01 & 0 & & & & & \\
\hline
\end{tabular}

When moral obligation was added to the regression analysis (step 2) a statistically significant increase in the $\mathrm{R}^{2}$ was observed. TPB with the addition of moral obligation accounted for $41 \%$ of the variance in intentions to engage in AD. Statistically significant regression coefficients for direct attitudes $(\mathrm{t}=-3.7$, $\mathrm{p}<.001)$, indirect attitudes $(\mathrm{t}=-2.6, \mathrm{p}<.05)$ were obtained with direct attitudes (beta $=-.29$ ) having a larger coefficient than indirect attitudes (beta $=-.19$ ). The hypothesis that the addition of moral obligation (beta $=-.24$ ) will increase the predictive value of TPB was supported.

A paired sample t-test was used to compare TPB variables in the monitored and unmonitored situations. Findings showed that there were statistically significant differences in the way respondents answered questions for the $\mathrm{SN}$ in the monitored situation $(\mathrm{M}=1.80, \mathrm{SD}=.63)$ and the unmonitored situations $(\mathrm{M}=2.03, \mathrm{SD}=.63)$ were statistically significantly different, $\mathrm{t}(234)=-5.54, \mathrm{p}<$ $.001, \eta^{2}=.12$. Significant differences were also found in $\mathrm{PBC}$ monitored $(\mathrm{M}=2.31, \mathrm{SD}=.65)$ and unmonitored situations $(\mathrm{M}=2.72, \mathrm{SD}=.78), \mathrm{t}(173)=$ -7.44, $\mathrm{p}<.001, \eta^{2}=.24$. Responses given for intentions in the monitored $(\mathrm{M}=1.89, \mathrm{SD}=.84)$ and the unmonitored situation $(\mathrm{M}=2.20, \mathrm{SD}=.88), \mathrm{t}$ $(228)=-5.01, \mathrm{p}<.001, \eta^{2}=.10$ showed statistically significant differences. These significant differences were also found when assessing moral obligations in the monitored $(\mathrm{M}=3.29, \mathrm{SD}=.73)$ and unmonitored situations $(\mathrm{M}=2.96, \mathrm{SD}=.81), \mathrm{t}(221)=6.29, \mathrm{p}<.001$, $\eta^{2}=.15$. Direct attitudes were not exempt from this trend as the responses given in the monitored $(\mathrm{M}=$ 4.57, $\mathrm{SD}=1.03)$ and unmonitored situations $(\mathrm{M}=$ 4.03, $\mathrm{SD}=1.16)$ were significantly different, $\mathrm{t}(157)$ $=7.61, \mathrm{p}<.001, \eta^{2}=.19$. The eta squared statistics for all the TPB variables indicated a large effect size. The hypothesis that participants will respond differently depending on the situation was accepted.

When moral obligation was added to the regression analysis (step 2) a statistically significant increase in the $\mathrm{R}^{2}$ was observed. TPB with the addition of moral obligation accounted for $41 \%$ of the variance in intentions to engage in $\mathrm{AD}$. Statistically significant regression coefficients for direct attitudes $(\mathrm{t}=-3.7, \mathrm{p}<.001)$, indirect attitudes $(\mathrm{t}$ $=-2.6, \mathrm{p}<.05)$ were obtained with direct attitudes (beta $=-.29$ ) having a larger coefficient than indirect attitudes (beta $=-.19$ ). The hypothesis that the addition of moral obligation (beta $=-.24$ ) will increase the predictive value of TPB is accepted.

The results of the Baron and Kenny's [19] simple mediation model analysis showed that justification has a partial mediating role between the TPB variables: indirect attitudes towards $\mathrm{AD}$, subjective norms, $\mathrm{PBC}$, and intention to engage in $\mathrm{AD}$. The effects in the model are all statistically significant from zero $(p<.05)$. The indirect effect of indirect attitudes on intentions is partially mediated by the respondents justification to engage in $\mathrm{AD}$ is further confirmed by the Sobel test $(\mathrm{z}=-2.06, \mathrm{p}<.05)$, which revealed a smaller indirect effect value $(-0.09)$ than the total effect $(-0.61)$. The bootstrapping $95 \%$ CI level (-.19, -.01) also confirms partial mediation. The indirect effect of PBC on intentions through respondent's justifications is confirmed by the results from the Sobel test that were significant $(\mathrm{z}=2.67, \mathrm{p}$ $<0.5)$ together with the bootstrapping $95 \%$ CI (.03, .16). The estimate of the indirect effect PBC on intentions to engage in $\mathrm{AD}$ through justification is 0.08 while the total effect is 0.3 indicating partial mediation.

Partial mediation between subjective norms on intention to engage in $\mathrm{AD}$ through respondents justifications is confirmed by the results from the Sobel test $(\mathrm{z}=2.70, \mathrm{p}<.05)$. The indirect effect value (0.09) was smaller than that of the total effect $(0.54)$, and the bootstrapping $95 \% C I(.03, .18)$.

The variable, direct attitude, in the monitored situation was different to the results of other variables. Justification was not an intervening variable between direct attitudes and intentions. Baron and Kenny's [19] simple mediation model reported no relationship between the justification and intentions to engage in $\mathrm{AD}$, deviating from the third step in the model. The Sobel test confirms that justification is not an intervening variable between direct attitudes and intentions $(\mathrm{z}=-1.15, \mathrm{p}>.05)$. The bootstrapping $95 \%$ CI $(-.11,-.03)$ reveals that the indirect effect is not significant from zero, and that justification does not have a mediating role in intentions and direct attitudes.

In the unmonitored situation, justification was found to be a partial mediator between the TPB variables: indirect attitudes, direct attitudes, subjective norms, PBC and intentions to engage in AD. All the effects from Baron and Kenny's model [20] were statistically significant from zero $(p<.05)$, revealing that justification is an intervening variable. The Sobel test results $(\mathrm{z}=-4.57, \mathrm{p}<.05)$ and the bootstrapping $95 \% C I(-.35,-.13)$, confirm the results found in the simple mediation model. The indirect 
effect $(-.23)$ was found to be smaller than the total effect (-.67) further verify that indirect attitudes and intentions are partially mediated by justification of cheating.

Justification partially mediates direct attitudes toward $\mathrm{AD}$ and intentions to engage in $\mathrm{AD}$ is corroborated by the results from the Sobel test $(\mathrm{z}=$ $3.08, \mathrm{p}<.05)$. The Sobel test revealed that the indirect effect (-.09) was smaller than that of the total effect (-.33) and the bootstrap results $95 \%$ CI (-.15, $.04)$ confirm the indirect effect is statistically significant from zero $(\mathrm{p}<.05)$.

The indirect effect (.19) on PBC on intentions to engage in $\mathrm{AD}$ through justification is smaller than the total effect (.54) making it statistically significant. The Sobel test $(\mathrm{z}=4.08, \mathrm{p}<.05)$ and the bootstrapping $95 \% \quad C I \quad(.11, .29)$ show that justification is considered to have a partially mediating role between $\mathrm{PBC}$ and intentions to engage in AD.

Justification has a partially mediating effect between subjective norms and intention to engage in $\mathrm{AD}$, as the variable effects in the Baron and Kenny's [20] are statistically significant $(p<.05)$. The Sobel test result $(\mathrm{z}=4.00, \mathrm{p}<.05)$ is significant, and the indirect effect (.17) is less that the total effect (.60) confirming the results from the simple mediation model. The bootstrapping $95 \%$ CI $(.08, .28)$ further substantiates these results.

Independent sample t-tests were used to compare gender means for the academic dishonest behaviour, justification and behavioural self-report scales. The results from the test for equality of variance were not significant $(p>.05)$ showing that equal variances can be assumed for the males and the female respondents. No statistically significant differences were found between the males and the females for the academic dishonest behaviour subscale $t(227)=-$ $.99, p>.05$ and for the behavioural self-report subscale, $t(227)=1.80, p>.05$. For the justification subscale, a statistically significant difference was noted between males and the females, $t(224)=2.37$, $p<.05$ with males having a greater mean score than females.

A one-way analysis of variance (ANOVA) was used to compare the mean differences within the variables by academic year of study (AYOS). The test of equality of variance was not significant $(p>$ .05). Findings show statistically significant differences between the first year, second year and third year students for the indirect attitudes subscale $F(2,215)=1.71, p<.05$ and for the behavioural selfreport subscale $\mathrm{F}(2,217)=3.78, \mathrm{p}<.05$. To determine exactly which group means differed significantly, the Scheffe test was carried out to do post hoc multiple comparisons. The results revealed that there are differences in the indirect attitudes towards $\mathrm{AD}$ between the first year and third year students $(\mathrm{MD}=0.3)$, with first year respondents having greater means than the third years. For the self-report subscale, the Scheffe test did not show any significant differences between academic year groups due to the adjustment for multiple tests.

\section{Discussion}

The results from this study showed that direct and indirect attitudes had a significant inverse relationship with intentions to engage in $\mathrm{AD}$. The findings of this study are similar to results of similar studies .[13,18] Although TPB is a sufficient predictive model in this SA tertiary institution, an investigation of independent variables confirmed the statistical significance of direct and indirect attitudes as predictors of intentions to engage in AD. Research has shown that TPB has much more predictive accuracy when investigating attitudes towards specific behaviour than when trying to investigate global attitudes [15].

The finding of this study of a significant relationship between subjective norms and an individual's intention to engage in $\mathrm{AD}$ is similar to other studies that have used TPB $[13,18]$. However, when other predictors were included in the multiple regression, subjective norms were not a significant predictor of intentions to engage in $\mathrm{AD}$. The reason why subjective norms were not significant as a predictor of intentions to engage in $\mathrm{AD}$, may be due to strong attitudes against AD reported in this study. Respondents inferred that their referent others will not condone engaging in $\mathrm{AD}$, leaving no room for intentions to engage in $\mathrm{AD}$ [1]. The residence of residences presents an opportunity for the transmission of norms, values and skills that encourage cheating [1].

A significant inverse relationship was found between moral obligation and intentions to engage in AD. This inverse relationship is different to similar studies on $\mathrm{AD}$ that have a positive relationship [13, 18]. Moral obligation in this study is a significant predictor for intentions to engage in AD. More importantly, it increased the predictive value of TPB as hypothesised. This confirms the findings by Beck and Ajzen [20] and Harding et al. [13]. An individual's attitude towards the behaviour as well as their moral obligation are key in informing intentions to engage in $\mathrm{AD}$ because of their belief system [15] and their ethics. The results from this study confirmed that respondents from different academic years of study: first, second and third years, had different indirect attitudes towards intentions to engage in AD. Previous studies have shown that age and academic year factors should be considered in $\mathrm{AD}$ as younger students are more likely to engage in $\mathrm{AD}$ than older ones [13]. Indirect attitudes guide ones behaviour by accessing beliefs about the likely consequences of engaging in the behaviour [14]. A closer inspection at these results found the 
differences between the first and third year respondents. Perceived negative consequences of engaging in $\mathrm{AD}$ for third year students is higher than for the first year students [10].This is because students expect to graduate at the end of their third year and engaging in $\mathrm{AD}$ would nullify the investments made over all their tertiary years. In this competitive society, one bad record on students' transcript may mean no graduation, no job and a bleak future [1].

This study found that some variables of TPB and intentions to engage in AD are partially mediated by the respondent's justification for cheating. Respondents in this study are more likely to justify cheating to avoid situations leading to failure, supporting the view by McCabe et al. [1] that the competitiveness of society influences AD. The mediation results are similar to those of Stone et al. [18] who found justification of $\mathrm{AD}$ to influence attitudes, subjective norms and PBC. Stone et al. suggested that justification of cheating is closely related to attitudes, subjective norms and PBC because it is a cognitive phenomenon. This means that justifying cheating will neutralise and trivialise the action leading to engaging in the behaviour In this study, respondents have strong attitudes against $\mathrm{AD}$ and yet there is self-reported cheating. These inconsistencies may lead to high levels of cognitive dissonance that increase the need to justify cheating [18].

\section{Implications for Practice}

According to Beck and Ajzen [20], it is much more difficult to understand and explain dishonest behaviours than socially accepted behaviours. The findings are important for institutions so they can formulate interventions and policies that will address and focus resources and energy on improving student knowledge of implications of AD. Policy makers in the respective faculties should ensure that referencing conventions applicable to that faculty are made known and taught to students together with the sanctions given should one engage in $\mathrm{AD}$ (Harding et al., 2007; Iyer\& Eastman, 2006;[13, 10]. This way, students will become aware of what constitutes $\mathrm{AD}$ in the monitored and unmonitored situations. It would be prudent for the different faculties within the tertiary institution to be aware of the $\mathrm{AD}$ engagement rates within the faculty in order to find suitable ways to curb the phenomenon.

When applying the TPB it is important to note that one of the variables: attitudes towards the behaviour, subjective norms and PBC, may be more important than the other depending on the behaviour in question and the situation [12]. In this study attitudes towards $\mathrm{AD}$ played an important factor in predicting intentions to engage in $\mathrm{AD}$. The TPB can be used to tailor intervention strategies in specific contexts by addressing beliefs that have been shown to differ significantly between intenders and nonintenders. Knowing answers to the 'what' and 'why' questions of behavioural beliefs, allows the institution to find appropriate ways and means to reduce the $\mathrm{AD}$ incidences [6].

This study was conducted using a cross-sectional research design which cannot capture changes in attitudes over changing academic year of study. The study did not conduct elicitation interviews or use focus groups and as a result runs the risk of monomethod bias. Conducting a longitudinal study to fully understand attitudes towards $\mathrm{AD}$, subjective norms, $\mathrm{PBC}$, moral obligation and even justification of $\mathrm{AD}$ will give researchers more understanding into $\mathrm{AD}$.

\section{References}

[1] McCabe, D.L., Trevino, L.K., \& Butterfield, K.D. (2001). Cheating in academic institutions: A decade of research.Ethics \&Behaviour, 11(3), 219-232.

[2] Bretag, T. \& Mahmud, S. (2009). A model for determining student plagiarism: Electronic detection and academic judgment. Journal of University Teaching \& Practice, 6(1), 50-60.

[3] Faucher, D., \& Caves, S. (2009). Academic dishonesty: Innovative cheating techniques and the detection and prevention of them. Teaching and Learning in Nursing, 4(2), 37-41. doi:[10.1016/j.teln.2008.09.003]

[4] Bernardi, R.A., Baca, A.V., Landers, K.S. \&Witek, M.B. (2008). Methods of cheating and deterrents to classroom cheating: an international study. Ethics \& Behavior, $\quad 18(4), \quad 373 \quad-\quad 391$. doi:[10.1080/10508420701713030]

[5] Riog, M. \&Caso, M. (2005). Lying and cheating: Fraudulent excuse making, cheating and plagiarism. The Journal of Psychology,139(6), 485-494.

[6] Etter, S., Cramer, J.J., \& Finn, S. (2006). Origins of academic dishonesty: ethical orientations and personality factors associated with attitudes about cheating with information technology. Journal of Research on Technology in Education, 39(2), 133-155.

[7] Wowra, S. A. (2007). Introduction to the special issue: Academic dishonesty. Ethics \&Behaviour,17(3), 211-214.

[8] Arhin, A.O., \& Jones, K.A. (2009). A multidiscipline exploration of college students' perceptions of academic dishonesty: Are nursing students different from other college students. Nurse Education Today, 29, 710714.doi:[10.1016/j.nedt.2009.03.001].

[9] Harper, M. G. (2006).High tech cheating. Nurse Education in Practice, 6(6), 364-371.

[10] McCabe, D.L. \&Trevino, L.K. (1997). Individual and contextual influences on academic dishonesty: a multi- 
campus investigation. Research in Higher Education, $38(3), 379-396$.

[11] Iyer, R., \& Eastman, J.K. (2006). Academic dishonesty: Are business students different from other college students? Journal of Education for Business, 82(2), 101-110.

[12] Kisamore, J. L., Stone, T. H., \&Jawahar, I. M. (2007). Academic integrity: The relationship between individual and situational factors on misconduct contemplations. Journal of Business Ethics, 75, 381-394. doi:[10.1007/s10551-006-9260-9]

[13] Ajzen, I. (1991). Theory of planned behaviour.Organizational Behavior and Human Decision Processes, 50, 179-211.

[14] Harding, T.S., Mayhew, M.J., Finelli, C.J., \& Carpenter, D.D. (2007).The theory of planned behaviour as a model of academic dishonesty in engineering and humanities undergraduates. Ethics and Behaviour, 17(3), 255-279.

[15] Ajzen, I., \& Fishbein, M. (2005).The influence of attitudes on behaviour. In Albarracin, D. Johnson, B.T. \&Zanna M.P. (Eds.), The Handbook of Attitudes (pp. 173 221). Mahwah, NJ: Erlbaum.

[16] Ajzen, I., \& Gilbert Cote, N. (2008).Attitudes and the prediction of behavior. In W.D. Crano\& R. Prislin (Eds.), Attitudes and Attitude Change (pp. 289-311). New York: Psychology Press.

[17] Murdock, T.B., \&Anderman, E.M. (2006). Motivational perspectives on student cheating: towards a integrated model of academic dishonesty. Educational Psychologist, 41(3), 129-145.

[18] Rettinger, D. A., \& Kramer, Y. (2009). Situational and personal causes of student cheating.Research in Higher Education, 50, 293-313. doi:[10.1007/s11162-008-9116-5].

[19] Beck, L., \& Ajzen, I. (1991).Predicting dishonest actions using the theory of planned behavior. Journal of Research in Personality, 25(3), 285-301.

[20] Baron, R. M., \& Kenny, D.A. (1986). The moderatormediator variable distinction in social psychological research: Conceptual, strategic and statistical considerations. Journal of Personality and Social Psychology, 51(6), 1173-1182. 